\title{
Educação Permanente em Saúde: narrativa dos trabalhadores de Saúde Mental de Betim/Minas Gerais
}

\author{
I ${ }^{1}$ Dirley Lellis dos Santos Faria, ${ }^{2}$ João Leite Ferreira Neto, ${ }^{3}$ Kênia Lara Silva, \\ ${ }^{4}$ Celina Maria Modena I
}

Resumo: A criação dos serviços substitutivos ao manicômio trouxe inúmeros desafios, entre eles, a formaçâo de seus trabalhadores. Frente a esse desafio foi necessário a formação em ato, nos próprios serviços. O presente estudo busca compreender esse fenômeno, a partir da trajetória dos trabalhadores de Saúde Mental do município de Betim, Minas Gerais. O referencial metodológico se baseou na pesquisa qualitativa orientada pela hermenêutica-dialética. Os instrumentos de coleta de dados foram entrevistas narrativas e grupo focal. Compreendemos que os trabalhadores aprenderam a trabalhar na atenção psicossocial dentro dos próprios serviços, a partir da equipe multiprofissional e dos seguintes dispositivos: reuniōes, fóruns, oficinas. Foram atores ativos, promovendo seminários e encontros diversos; bem como tiveram, em certos momentos, supervisôes clínico-institucionais. A integração ensino-serviço também favoreceu a Educação Permanente dos trabalhadores. No entanto, nos últimos anos, tem havido dificuldades para sustentar tal formação.

> Palavras-chave: educação permanente em saúde; saúde mental; pesquisa qualitativa.

\author{
1 Fundação Oswaldo Cruz - \\ Instituto René Rachou. Belo \\ Horizonte-MG, Brasil (dirleylellis@ \\ yahoo.com.br). ORCID: 0000- \\ 0001-5089-8160 \\ 2 Pontifícia Universidade Católica de \\ Minas Gerais. Belo Horizonte-MG, \\ Brasil (jleite.bhe@terra.com.br). \\ ORCID: 0000-0003-3900-508X \\ ${ }^{3}$ Universidade Federal de Minas \\ Gerais. Belo Horizonte-MG, Brasil \\ (kenialara17@gmail.com). ORCID: \\ 0000-0003-3924-2122 \\ ${ }_{4}^{4}$ Fundação Oswaldo Cruz - \\ Instituto René Rachou. Belo \\ Horizonte-MG, Brasil (celina. \\ modena@fiocruz.br). ORCID \\ 0000-0001-7966-9951
}

Recebido em: 04/09/2019 Aprovado em: 16/12/2019 Revisado em: 24/05/2021 
A Reforma Psiquiátrica no Brasil é produto de um movimento social. Em um contexto de lutas por democracia, fortaleciam-se as reivindicações por saúde pública e pelo tratamento em liberdade, trabalhadores, intelectuais e familiares se uniram contra os manicômios, marcados pelos horrores do descaso e da violência. Esse movimento contestatório foi reforçado pela presença de personalidades como Basaglia, Castel, Goffman e Foucault, que traziam suas ideias e denúncias contra as instituições totais (AMARANTE, 2015). Nesse contexto, a "Luta Antimanicomial" terá nas décadas de 80 e 90 sua efervescência.

Inicialmente foram criados serviços substitutivos aos hospitais psiquiátricos em algumas cidades brasileiras, sendo referência nacional a intervenção feita em Santos (SP), em 1989. Esses serviços emergem dentro do recém-implantado Sistema Único de Saúde (SUS), com novas formas de trabalho, novas ideias e a necessidade de novos conhecimentos e práticas. Mas a realidade era outra: os trabalhadores não tinham formação para esse fim. Ferreira Neto (2017) aponta que, embora o SUS constitua, a partir da década de 1990, um significativo mercado de trabalho para os profissionais da saúde, os cursos de graduação mantinham uma tradição formativa calcada na clínica liberal-privada.

Nesse sentido, era preciso capacitar em ato, o próprio trabalho "abriu espaço para o desenvolvimento de certa tradição de uma 'formação em serviço', bastante frequente em todos os municípios e secretarias de estado do país” (FERREIRA NETO, 2017, p. 144). Esta tradição esteve também presente na construção da política de "recursos humanos" para o SUS, através do conceito de Educação Permanente.

O termo Educação Permanente estava sendo utilizado na América Latina pela UNESCO desde a década de 70 (GRILLO, 2012), mas é a partir da Conferência de Alma Ata (1978), com o novo paradigma de cuidado da saúde, focado na Atenção Primária, e com a necessidade de mudanças nos processos de trabalho e na educação dos trabalhadores, que este termo se afirma no campo da saúde.

As discussões sobre a Educação Permanente em Saúde (EPS) ocorreram no Brasil sob os auspícios da Organização Pan-Americana de Saúde (OPAS), com foco no processo de trabalho, na valorização das vivências e práticas em saúde dos sujeitos sociais, com uma proposta de reorientação dos processos educacionais em saúde, tendo em vista a aprendizagem no trabalho (CAMPOS, SENA e SILVA, 2017). A Organização estabelece a EPS como uma proposta educativa realizada nos serviços para refletir e intervir sobre o processo de trabalho, visando melhorar a qualidade 
desses serviços e suas condiçôes de trabalho (OPAS, 1992). A atividade é considerada como mola propulsora da aprendizagem.

O protagonista principal do processo educativo deve ser a equipe, que, por sua vez, deve ser multidisciplinar e desenvolver um trabalho interprofissional. Os trabalhadores devem ser capazes de analisar seu contexto de trabalho, identificar os problemas emergentes do serviço, promover a participação e tomar decisôes. Resumidamente, a EPS seria constituída por: educação no trabalho, pelo trabalho e para o trabalho; pedagogia da problematização; participação ampliada; enfoque estratégico e interprofissionalidade (CAVALCANTI; GUIZARDI, 2018).

No Brasil, essa proposta de educação entrou oficialmente para a agenda do SUS como política pública no início dos anos 2000. Temos documentos governamentais importantes que trazem a concepção dessa época. A Norma Operacional Básica em Recursos Humanos (NOB/SUS-RH), em sua última versão (BRASIL, 2005), a define como um processo contínuo de aquisição de informaçóes e conhecimentos, por meio de escolarização formal ou não formal, de vivências, de experiências laborais e emocionais, no âmbito institucional ou fora dele, tendo como objetivo melhorar e ampliar a capacidade laboral do trabalhador, em função de suas necessidades individuais, da equipe e da instituição em que trabalha.

Em 2004, a EPS ganhou a condição de "Política Nacional de Formação e Desenvolvimento para o SUS: Caminhos para a Educação Permanente em Saúde" (BRASIL, 2004), sendo considerada como a realização do encontro entre o mundo da formação e o mundo do trabalho, no qual o aprender e o ensinar deveriam se incorporar ao cotidiano das organizaçóes de saúde.

Para os autores desse documento, o processo de formação dos trabalhadores do SUS requereria ações no âmbito da formação técnica, da organização do trabalho, da interação com as redes de gestão e de serviços de saúde, bem como com o controle social - Quadrilátero da Formação (CECCIM; FEUERWERKER, 2004). A proposta era envolver os diferentes atores na mudança de rumos das políticas públicas do setor.

No documento "Política Nacional de Educação Permanente em Saúde" (BRASIL, 2009), a EPS é reafirmada como aprendizagem no trabalho, baseandose na aprendizagem significativa e na possibilidade de transformar as práticas profissionais, levando em consideração os conhecimentos e as experiências que as pessoas já possuem. 
Silva et al. (2019) identificam diferentes discursos que retratam o processo histórico da EPS no Brasil: o discurso da centralidade do trabalho (adestramento, instrumentalização e educação profissional para atender às demandas dos serviços) convivendo com o discurso da centralidade dos sujeitos (expresso na educação popular e na identificação das necessidades dos sujeitos para o processo de aprender). Verifica-se também o discurso político-institucional do ordenamento e mudança da formação, no qual o Estado é o regulador na formulação das políticas públicas no campo da saúde e da educação. Neste sentido, podemos acentuar o caráter múltiplo do conceito de EPS no Brasil.

Considerando o exposto, este estudo tem como objetivo compreender a trajetória de formação dos trabalhadores de Saúde Mental de Betim/MG, um dos municípios pioneiros da Reforma Psiquiátrica no Brasil.

\section{Percurso metodológico}

Trata-se de pesquisa de abordagem qualitativa orientada pela hermenêuticadialética, a partir da concepção de Minayo (2008, 2014). Para a autora, a combinação entre a hermenêutica e a dialética faz a síntese dos processos compreensivos e críticos.

O cenário do estudo foi o município de Betim/MG. Com uma população de 427.146 habitantes, está localizado a $30 \mathrm{~km}$ de Belo Horizonte. A partir da década de 90, o município teve um papel pioneiro na Reforma Psiquiátrica brasileira pela implantação de uma rede de serviços substitutivos ao hospital psiquiátrico, constituindo uma experiência que teve destaque nacional (SILVA, 2013).

A rede de Saúde Mental de Betim busca oferecer as várias linhas de cuidado a pessoa com sofrimento mental, conforme preconizado pela Rede de Atenção Psicossocial-RAPS (BRASIL, 2011). Em 2017 havia três CAPS para atendimento de adultos, dois dos quais tipo III e um tipo I, um CAPSad tipo III, um CAPSi, um centro de convivência e três moradias protegidas. Ademais, contava também com 13 profissionais na Atenção Básica, referenciando 17 unidades.

Foram utilizados entrevistas narrativas e grupos focais como estratégias metodológicas. Segundo Onocko Campos et al. (2013), as narrativas dão um sentido às histórias vividas, buscando sua compreensão. Foram entrevistados profissionais de diferentes categorias e locais de trabalho, bem como realizados dois grupos focais, conforme especificado na tabela 1 (em anexo). 
As entrevistas foram realizadas presencialmente, no local de trabalho, pela primeira autora, entre 2017 e 2018. Os trabalhadores foram convidados a narrar livremente sobre sua formação em Saúde Mental (SM). O primeiro grupo focal foi realizado no final de 2017, em um espaço próprio para reunióes da rede de Betim, com a participação de duas pesquisadoras (uma como mediadora do grupo e a outra como observadora). Durante o processo de pesquisa, foi utilizado o critério de saturação, finalizando a coleta, quando os temas se tornaram repetitivos e as informações suficientes para a investigação (MINAYO, 2014).

Foram realizadas várias leituras do material, buscando entender os textos "neles mesmos" (MINAYO, 2014). Esse exercício permitiu apreender as ideias centrais e elencar temas abordados, como organização do trabalho, formação em saúde mental, desafios e contradiçóes do trabalho em SM. Em seguida, foi construída uma narrativa comum a partir desses temas, narrativa esta apresentada em julho de 2019, no segundo grupo focal, sendo que todos os participantes da pesquisa foram convidados. Com isto, foi possibilitado aos integrantes do grupo retificar, discutir e validar esta narrativa, assim como coube a esse grupo interpretá-la e legitimála, constituindo o que Gadamer (1997) conceitua de "círculo hermenêutico". Nesse processo, os sujeitos da pesquisa "passaram duas vezes pelo mesmo lugar, mas o fizeram em atitudes diversas, compreendendo de maneira sempre ampliada" (ONOCKO CAMPOS, 2013; p.270).

A pesquisa "Trajetória da Formação dos Trabalhadores de Saúde Mental do município de Betim/MG” foi desenvolvida no âmbito de investigação de doutorado da primeira autora. Foi aprovada pelos comitês de ética da Prefeitura de Betim/MG, em 09 de Julho de 2017, e do Instituto René Rachou-FIOCRUZ/MG, em 14 de Junho de 2017 (CAAE-68499517.6.0000.5091), não havendo conflitos de interesses e nem financiamento externo.

\section{Resultados e discussão}

\section{Primeiros anos - protagonismo dos trabalhadores e da gestáo}

A maioria dos trabalhadores, quando chegou aos serviços de Betim, não tinha formação específica em SM, com poucas exceções. No início, somente os psiquiatras e alguns psicólogos tinham experiência na assistência a pacientes psicóticos, contudo, em hospitais psiquiátricos ou ambulatórios. Os entrevistados relataram a existência 
de "um grupo de profissionais militantes que, junto a uma gestão mais progressista, se dispuseram a construir uma rede de serviços de SM do município" (Grupo focal 2).

Esse grupo tinha uma formação diferenciada: alguns psicólogos com especialização em SM na Escola de Saúde Pública de Minas Gerais (ESPMG) e alguns psiquiatras oriundos do Programa de Residência Médica do Instituto Raul Soares. Foram os alunos desse Programa de Residência, por exemplo, os responsáveis pela organização do III Congresso Mineiro de Psiquiatria, em 1979, tendo como convidados Robert Castel e Franco Basaglia. Nessa oportunidade, houve diversas denúncias sobre a realidade dos hospitais psiquiátricos mineiros, especialmente do Hospital Colônia de Barbacena (ARBEX, 2013).

Em 1986, a ESPMG também inicia um curso de especialização em Saúde Mental visando capacitar profissionais para sustentar projetos alternativos à lógica manicomial. Consolidava-se o movimento pela Reforma Psiquiátrica no estado e no Brasil (NUNES, 2009). Alguns trabalhadores de Betim surgem então, dessa formação.

Minha residência foi no Raul Soares. Eu entrei num momento em que se pregava a desconstrução do hospital. Estava num momento de muita luta. No Raul, ainda existia um movimento de Antipsiquiatria. Apesar de ser algo já antigo, existia. Foi uma residência de muita briga, de muita luta, e muito em volta da luta antimanicomial. PA1

A grande maioria dos trabalhadores, no entanto, não tinha como proposta trabalhar na área de SM - tanto aqueles que entraram em meados de 1994-1995, quanto os que chegaram anos depois, uma vez que os concursos realizados eram para o SUS de forma geral.

Embora os profissionais não tivessem formação específica e/ou experiência em serviços substitutivos ao manicômio, quando entraram na rede buscaram se formar, individualmente ou no coletivo. No início, buscaram amparo teórico para suas práticas em grupos de estudos, grupos de pesquisa, especializaçôes e outras pós-graduaçóes. Os próprios trabalhadores se mobilizaram em busca de formação. Sentiam-se implicados com o processo de construção dos serviços. Mesmo aqueles que não eram militantes se envolveram nesse processo, seduzidos pela proposta ou até mesmo para se adaptarem ao grupo.

Eu acho que a equipe, de um modo geral, não estava preparada, mas a equipe estava muito junto. Esse processo de reunião de equipe possibilitava a quem tinha um percurso maior, ou na militância ou propriamente com os casos mais graves, ajudasse os demais... A gente estava sempre numa construção, né?! TO1 
Podemos concordar com Merhy, quando fala da necessidade de uma pedagogia da implicação, ou seja, "implicação ético-política do trabalhador no seu agir em ato, produzindo o cuidado em saúde, no plano individual e coletivo, em si e em equipe" (MERHY, 2005, p. 174).

Em suas narrativas, os entrevistados descreveram a preocupação com a inserção de novos trabalhadores. Os colegas ajudavam no desenvolvimento das funçóes, incentivando o investimento pessoal no trabalho, bem como estimulando a busca de novos conhecimentos. A formação se dava a partir da equipe e/ou nela própria.

Todos nós viemos sem saber o que íamos encontrar, eu aprendi com eles. Com o pessoal que estava aqui, o pessoal mais antigo. A1

Eu considero que a minha formação se deu a partir da minha entrada em Betim, que foi o primeiro CAPS 24 horas, onde eu comecei a trabalhar e de fato a lidar com essa clínica, no corpo a corpo. Fui aprendendo a trabalhar nessa questão de equipe. $\mathrm{Na}$ época, claramente, sem uma hierarquia vertical, mas uma coisa mais horizontalizada. Em termos de responsabilização pelos casos, de condução partilhada. Uma coisa que não existe na escola de medicina e nem mesmo nas residências tradicionais. [...] Eu preciso aprender o que esse povo está fazendo. Eu náo aprendi isso na escola, nem na residência. Foi aí que eu fui buscar outros espaços de interlocução, de conversa com outros campos de saber fora da medicina; porque eu vi que o que aprendi não bastou. PA2

Podemos comprovar a força da equipe no processo de EPS: a equipe de trabalho se converte em veículo para a reorganização de significados e práticas, transformando o "capital passivo" do conhecimento (conhecimento científico, sistemático e relevante) em "capital ativo", expressado em conhecimento significativo a partir da reflexão sobre a ação (HADDAD; ROSCHKE e DAVINI, 1994). Assim, podemos dizer que os trabalhadores de Betim vivenciaram a EPS considerando o trabalho como fruto da interação dos profissionais da equipe entre si e com os usuários, sendo esse 'entre', como aponta Cavalcanti e Guizardi (2018), o principal dispositivo dos processos educacionais.

Os próprios trabalhadores assumiram o papel de formadores: organizavam seminários, cursos, encontros e outras estratégias de educação mais participativas (oficinas, fóruns) com temas eleitos pelo coletivo. Nesse sentido, a formação foi se integrando aos serviços (BRASIL, 2004)

O município também recebeu convidados engajados no Movimento da Luta Antimanicomial e/ou profissionais de outros serviços (tais como os de Santos, Campinas). Vale lembrar que Belo Horizonte foi um importante foco de influência 
para os serviços de SM em Betim, tanto pela proximidade quanto pelo fato de alguns profissionais com jornada de 20 horas trabalharem concomitantemente nos dois municípios. Em 1995, Betim sediou o II Encontro Nacional da Luta Antimanicomial e, em 1998, o V Encontro Nacional de Usuários e Familiares (AMARANTE, 2015). Foi uma década de muito protagonismo, já relatada por outra pesquisadora:

[...] a intençáo de construir uma rede de atendimento ao portador de sofrimento psíquico
partiu da organizaçáo de um grupo de trabalhadores. Neste sentido, foi um marco para o
desenvolvimento de Betim e região o compromisso assumido entre o governo municipal
e os trabalhadores que atuavam no campo da saúde mental, no início da década de 1990,
em construírem uma rede de atendimento - orientada pelos princípios do SUS e do mo-
vimento pela Reforma Psiquiátrica - que evitasse a internaçáo e a cronificaçáo de pessoas
em hospitais psiquiátricos. [...] (NUNES, 2009, p.117).

Anos mais tarde o contexto é outro. Com a implantação nacional da política de SM (BRASIL, 2001), houve também em Betim uma expansão dos serviços e, em 2006, é realizado, novamente, um grande concurso e um número significativo de profissionais é inserido na rede de SM, muitos deles despreparados para esse trabalho.

Náo pensei que de fato eu ia parar na SM. Quando eu fiz concurso, eu estava ainda na graduação, eu fiz para a saúde de uma forma geral em Betim e não imaginava que seria chamada e poderia estar escolhendo entre urgência ou inserir em serviços de SM. [...] eu sinto até hoje uma ausência, uma falta, uma falha, vamos dizer assim, de capacitação específica pra trabalhar em SM. (AS4)

Minha experiência em SM era bem restrita aos estágios obrigatórios, pouca coisa eu fiz em SM. (TO4)

Os trabalhadores, de forma geral, continuam chegando sem preparação para o trabalho em SM, que demanda uma equipe multiprofissional, ultrapassando, portanto, a educação uniprofissional geradora de especialistas; demanda também uma educação interprofissional, entendida como o aprendizado compartilhado com estudantes e profissionais de diversas áreas, na perspectiva do trabalho integrado (PEDUZZI, 2017). A formação em serviço continua sendo essencial, bem como a integração ensino-serviço. Mas como ela acontece na SM? Que dispositivos são importantes?

\section{O trabalho como espaço de formação}

Todos os participantes consideraram que foi, principalmente, dentro dos serviços que aprenderam a trabalhar em SM, num processo de educação permanente. 
Aprendi muito. O que mais eu aprendi de SM foi no trabalho... Na convivência com o paciente e na discussão com os colegas... Eu aprendi muito com colega assim, no conversar, informal: "Isso é o quê?". A crise, a questấo das patologias, a medicação também, tudo que eu sei de medicação não foi em Pós, foi dentro do serviço, com colegas... A gente vai trocando experiência com a especialidade de cada um. AS1

Merhy (2015) destaca o cotidiano do trabalho como uma escola permanente na qual há não só produção de novos conhecimentos construídos coletivamente, como também novos processos de formação, sem que se tenha formalmente designado esse como lugar de capacitação do trabalhador para o exercício das suas funçóes, fato verificado nas narrativas dos trabalhadores.

Os profissionais estáo sempre aprendendo, seja com os usuários, seja com os colegas. Aprendem no dia a dia, conversando, negociando, manejando situaçóes. Aprendem no contato pessoal, na relação com o outro, no retorno de cada um. Cada usuário demanda um projeto específico e implica açôes múltiplas e articulaçôes junto à rede intrassetorial e intersetorial.

Esse é o maior aprendizado, porque os próprios pacientes vêm com uma característica muito própria do caso deles. Os nossos casos são muitos ricos. Têm casos que a gente tem que discutir e acompanhar junto ao CRAS, têm casos de crianças, têm que acompanhar com o CREIAS, tem caso com interface com a família acolhedora, a gente está lá fazendo reunião com a família acolhedora. Tem caso que vai pro hospital, que é caso mais grave. A gente tem que discutir lá essa questáo médica, essas questôes todas. [...] a gente pensa em Centro de Convivência, para poder fazer paralelo ao tratamento no CAPS. Então acaba que a gente vai circulando muito porque o caso geralmente é muito rico. TO4

As reunióes de equipe (semanais) foram avaliadas como espaços privilegiados para discussão e construção coletiva dos casos clínicos e projetos terapêuticos. Constituíram-se como espaços de formação clínica, de construção de conhecimento coletivo, bem como de posicionamentos políticos importantes para estabelecimento de mudanças nos processos de trabalho. Neste sentido, podemos reconhecer a concepção de EPS tal como foi colocada pela política nacional (BRASIL, 2004).

Dentro do contexto, a 'passagem de plantão' também foi citada como um momento importante para essa construçáo coletiva e aprendizado dos trabalhadores, favorecendo a integralidade das açôes.

Eu acho que tem um ganho na SM que é a participação na reunião de equipe. A participação do plantão como um todo, essa coisa de estar junto, discutindo quais os pacientes que deveriam ser buscados naquele dia; a participação da equipe na construçáo do caso. Entender por que o técnico de referência optou por colocar o paciente na permanência dia, né! Eu acho que a equipe de enfermagem tem algo que é do olhar cotidiano, de ver aquele paciente 
todo dia, e poder dizer coisas... que é desse observar. Às vezes, percebemos coisas que o técnico de referência não consegue pelo curto tempo que ele está com aquele paciente. T1

Em alguns serviços, no entanto, principalmente nos CAPS III - nos quais há um número maior de profissionais, especialmente da enfermagem -, observamos diversos desafios para sustentar esses dispositivos, em razão da dificuldade de reunir toda a equipe -muitos trabalham em turnos distintos - pelas inúmeras demandas dos serviços e pela própria desmotivação dos trabalhadores.

Eu tenho ficado angustiada com isso. É um espaço de formação constante que eu acho que é esta reunião de equipe. Porque é um horário protegido. Aqui em Betim acontece nas sextas-feiras. Mas aí o que acontece? Tudo o que vai acontecer no município é na sexta-feira. E então a gente sai várias vezes desta reunião, ela não acontece muitas vezes. E na verdade este horário não é protegido para todos. Como os nossos serviços são muito inchados está muito difícil para todo mundo parar e estar ali. [...]. A reunião não consegue ter tempo suficiente para discutir todos os casos. Para falar da especificidade de cada caso, para você aprender o que está acontecendo. Tem que passar um monte de informação: uma mudança do horário da prefeitura, do horário de não sei o quê... A reunião não é mais suficiente e isso tem me angustiado muito. Eu acho que gente perdeu muito em espaços de formação e a gente percebe isso se deteriorando no serviço [...] F3

Embora reconheçam a importância desses espaços, estão impotentes diante da grande demanda de trabalho e da burocratização desses dispositivos, não se reconhecendo mais como protagonistas desse processo no cotidiano.

Os fóruns intersetoriais também foram citados como espaços de discussão e formação: neles participam diversos atores da rede intrassetorial e intersetorial para discutir os casos mais complexos. No início, foi uma iniciativa dos próprios trabalhadores, eles mesmos os coordenavam e organizavam, num movimento instituinte.

Nos fóruns se elegia um caso e os atores daquele caso - escola, centro de reabilitação, CRAEI - sentava mesmo para discutir e era muito bacana, muito importante mesmo. Estava médico, quem acompanhava como Técnico de Referência, a escola... Era uma discussão muito rica. E1

Atualmente, os fóruns intersetoriais foram instituídos oficialmente como dispositivos da RAPS Betim. Uma vez por mês, os profissionais da SM se dirigem para outros serviços nas diversas regiôes da cidade, reunindo-se com os demais trabalhadores da rede. A proposta é a integração dos diferentes serviços para atender aos casos mais complexos no próprio território e a formação dos trabalhadores da Atenção Básica em saúde mental. 
As supervisóes também foram apontadas como essenciais para a formação dos trabalhadores de Betim - aquelas realizadas individualmente, em um modelo mais clássico, por investimento do próprio profissional ou as viabilizadas pela gestão municipal ou federal, denominadas "supervisão clínico-institucional", como dispositivo estratégico originado das necessidades concretas do novo modelo de atenção psicossocial (DELGADO, 2013).

Constatamos que os fóruns e as supervisóes clínico-institucionais de Betim caminham na direção da proposta da Política de EPS (BRASIL, 2004), constituindose como espaços para a discussão e a mudança do processo de trabalho da equipe de saúde mental, conforme analisado em outras pesquisas (SAMPAIO et al., 2011; SILVA et al., 2013).

A supervisão clínico-institucional, segundo Radke e Ceccim (2018), objetiva qualificar a prática dos profissionais que atuam diretamente na ponta, no atendimento ao usuário e promover o debate, a construção e avaliação da rede de atenção psicossocial. Geralmente, é escolhido um caso que traz questôes para o serviço, possibilitando um cuidado mais adequado às suas necessidades. Para isto, é convidado um profissional de fora, com experiência e formação em saúde mental, para orientar na discussão do projeto terapêutico. Os profissionais de Betim reconhecem esse dispositivo como importantíssimo para o trabalho, na construção dos casos estudados e concedendo subsídios para outros, integrando a teoria e a prática.

As supervisôes clínicas, clínico-institucionais, foram um marco muito importante neste meu percurso. (...) Ainda que fosse sobre um viés muito diferente, a psicanálise, que não era minha formação, mas eu acho que as supervisões clínico-institucionais foram apurando a minha escuta [...]. TO2

Nesse processo, reconhecem a importância dos supervisores se expressarem numa linguagem acessível a todos, pois, em muitos momentos, os termos por eles utilizados, ancorados na teoria psicanalítica dificultaram a compreensão de parte da equipe, como observamos nos depoimentos a seguir.

Nos cinco anos que fiquei no Cersami (CAPSi) a gente teve supervisóes interessantes. Complicadas, às vezes. Como a minha formação não é tão específica, tinha termos, tinha algumas coisas assim que eu não entendia. T1

Na época do estágio em SM eu tinha essa mesma sensação de estrangeira, porque as supervisóes no CERSAM Santa Tereza \{Belo Horizonte\} eram todas em psicanálise e não era uma psicanálise acessível que vim a ter depois. Era uma psicanálise de desenhar matema 
no quadro, para uma equipe que tinha técnico de enfermagem. Então, aquilo não servia, não entrava pra mim. ... É isso. Entrei na cara e na coragem na SM aqui de Betim. TO2

Em Minas Gerais, observa-se uma forte influência da psicanálise lacaniana. Muitos dos supervisores eram psicanalistas, o que contribuiu para uma escuta subjetiva de cada usuário e para o atendimento de pacientes psicóticos, apontando para projetos terapêuticos singulares, abertos a constante revisão e atentos para a imprevisibilidade permanente dessa condição (VASCONCELOS, 2009). Contudo, segundo Ferreira Neto (2017), essa hegemonia da psicanálise dificultou o debate interdisciplinar no campo da saúde mental, sendo que a ênfase na dimensão clínica levou à sobrevalorização da intervenção intrassubjetiva, em detrimento de práticas ampliadas de intervenção no campo de interação entre os sujeitos e nos seus territórios. Observamos em Betim dificuldades no trabalho de inserção social dos usuários - talvez devido ao centramento nessa perspectiva subjetiva e/ou porque as próprias condiçóes de trabalho têm dificultado a ampliação do cuidado. Esse é um tema que merece ser aprofundado em futuros estudos.

[...] a nossa clínica perdeu muito nos últimos anos; essa possibilidade de outro viés de trabalho. Você precisa de tempo para construir uma inserção social de um paciente, após uma ruptura psicótica ou de outra ordem no campo da saúde mental. E, hoje, a gente fica muito apagando incêndios. A equipe mínima... muita gente já vem desmotivada. Então, é difícil você fazer isso. Eu não gosto deste termo reabilitação social. Isto eu aprendi na Psicanálise: o indivíduo, principalmente o psicótico, vai construir, ao longo de sua vida, alguns pontos de suplência que dão uma certa ancoragem. E cada crise quando há aquilo que claudica, falha, ele tem que construir o novo. Então, é sempre uma inserção social..., uma nova inserçấo desse sujeito no contexto, seja social, familiar, laborativo. PA2

Nos últimos anos, os profissionais reconhecem a falta das supervisóes como fator que empobrece a formação e a clínica. O que se tem alcançado, em alguns serviços, são supervisóes esporádicas em parceria com o curso de medicina do município, que são promovidas por um professor como contrapartida ao internato ali realizado, o que demonstra a importância da política de integração ensino-serviço do município, mas também sua insuficiência.

Esses dados reafirmam o que já havia sido levantado em 2013 pela pesquisa "Avaliação dos Centros de Atenção Psicossocial dos estados de Minas Gerais, Rio de Janeiro e Espírito Santo", realizada pelo Instituto de Psiquiatria da Universidade Federal do Rio de Janeiro, sobre o fato das supervisóes clínico-institucionais não terem se consolidado como recurso de qualificação dos CAPS. Tal pesquisa 
“aponta para as dificuldades não apenas da consolidação desta importante metodologia de acompanhamento da clínica no território, mas igualmente para a própria fragilidade da rede de atenção psicossocial” (DELGADO, 2013, p. 26); o que se constatou em Betim/MG.

\section{Integração ensino-serviço}

Os serviços de SM do município têm recebidos estagiários e residentes ao longo de sua história, numa proposta de integração ensino-serviço. A partir das iniciativas da Política Nacional, alguns profissionais participaram de projetos como o Programa Nacional de Reorientação Profissional para a Saúde (PróSaúde) e o Programa de Educação pelo Trabalho para a Saúde (PET-Saúde), mais especificamente o PET- Saúde Mental, Crack e outras drogas. Esses programas visavam impulsionar mudanças na formação para o trabalho em saúde pública e em saúde mental, injetando recursos financeiros e estimulando o desenvolvimento de atividades de formação e estágios, complementares àquelas da estrutura curricular pré-existente, e promovendo uma aproximação real com os campos de formação e os serviços (BRASIL, 2008; 2009).

Os trabalhadores de Betim reconhecem a importância da integração ensinoserviço não só para a formação de estudantes, mas também para o próprio processo de educaçáo permanente. Aqueles que se envolveram diretamente nesses projetos de formação avaliam que aprenderam muito ao "estudar e se preparar para acompanhar os alunos e dar supervisóes" $P 2$. Os alunos são representados como "pessoas de fora" que trazem questôes importantes para a reflexão do trabalho realizado. Entendem esse lugar de formador como um lugar também de aprendiz: "ao ensinar você aprende, pois precisa responder pelo que faz. Precisa refletir sobre seu trabalho para sustentar sua posição"TO1.

A residência em psiquiatria, que foi iniciada no município em 2012, e a residência multiprofissional em saúde mental, que se desenvolveu de 2010 a 2016, em parceria com a Escola de Saúde Pública (ESPMG) ou com a PUC Minas, foram importantes estratégias de formação interprofissional. Infelizmente, a multiprofissional não se manteve. Observamos, novamente, um recuo na formação em saúde mental no município, reflexo da falta de investimento na saúde pública. Os trabalhadores reconhecem e lamentam a extinção desse dispositivo. 
Esse momento da residência foi fundamental. Você cria uma formação para as pessoas estarem na rede. Um estudo e uma prática. Você aprende a trabalhar, fazendo. Aprende trabalhando. Eu vi muitos residentes passarem por aqui e a forma positiva que eles falam de aprender fazendo. É outra história! P2

Esses dados confirmam a recente pesquisa "Residência Integrada de Saúde Mental de Belo Horizonte", na qual constatou-se que essas experiências de residências constituem um espaço privilegiado de formação para o SUS, sustentando uma formação teórica vinculada às práticas e pautada no trabalho em equipe na lógica interdisciplinar, com grande potencialidade para o fortalecimento da atenção psicossocial, por meio da efetivação da interprofissionalidade e das práticas colaborativas entre trabalhadores (LIMA; PASSOS, 2019).

Verificamos que essas residências, além de formarem novos profissionais para o trabalho a partir da realidade do SUS, buscando uma escuta qualificada e o trabalho em equipe, mobilizaram também os trabalhadores da rede a continuarem neste processo de educação permanente. Os participantes puderam participar das aulas teóricas durante os anos de parceria com a ESPMG.

Depois veio a formação na ESPMG, a formação aprofundada em SM, que foi ligada à residência multiprofissional. Eu acho que aí mudou totalmente o meu percurso. Impressionante tanto que agregou, foi uma formação muito profunda, de $800 \mathrm{hs}$. TO2

Tivemos a oportunidade de começar a participar dos seminários; foi um convite ao trabalhador para estar participando das turmas. Nossa! Pra mim foi maravilhoso estar lá. ... Discutindo temas teóricos e práticos. Os residentes levavam a visão que tinham dos serviços para serem discutidos e as situações que rolavam com os pacientes e também tinha teoria, os casos clínicos... Foi riquíssimo! Uma oportunidade maravilhosa para minha formação. E1

Os trabalhadores também puderam refletir sobre o próprio processo de construção do conhecimento e da educação para o SUS:

A residência, eu acho que foi um momento importante. Depois de muitos anos no trabalho eu fui participar primeiro da residência como preceptora e depois como coordenadora. Isso me fez pensar muito no processo de formação: como deve ser a formaçáo do profissional para o SUS? E para a SM? O que é necessário saber? O que é importante? Que conhecimentos a gente têm acumulado nesses anos que precisa ser transmitido? Esse saber que a gente constrói na prática, que é fundamental, e que, muitas vezes, entra em choque com o que a academia pensa de um saber mais teórico, de uma forma mais sistematizada, dentro dos autores e tal. Foi um momento que me fez refletir muito sobre isso. A gente tem um saber, a gente construiu um saber, coletivamente... E daí a importância de se transmitir isso, para que quem chega não comece do zero. A residência foi um momento assim, que mexeu com isso. TO1 
Amarante (2015) afirma que a reforma psiquiátrica tem várias dimensôes, entre elas uma dimensão teórico-conceitual ou epistêmica, apontando que tal dimensão é muito importante, no entanto, é muito pouco abordada. Esse autor considera que é necessário que as pessoas que atuam na área da saúde mental aprendam a refletir sobre os conceitos e processos que definem o que é ciência, como se produzem conhecimentos, como estes se legitimam, além das relações entre saber e poder. A experiência da residência multiprofissional em Betim possibilitou tal dimensão.

Percebemos, também, ressonâncias desse processo na atual organização da residência de psiquiatria. Essa vem construindo uma preceptoria mais horizontal, sendo o preceptor "um servidor público, trabalhando na equipe juntamente com o residente” PA2. Busca-se uma relação mais próxima, na qual ambos estão atuando e compartilhando suas clínicas, num processo conjunto: "O preceptor não é um supervisor, mas alguém, com um pouco mais de experiência, que está aprendendo junto" PA2. Neste sentido, os trabalhadores reconhecem a importância de se ter uma metodologia mais participativa e menos prescritiva no processo ensinoaprendizagem.

O apoio matricial ainda não é consolidado em Betim, devido ao baixo número de trabalhadores de SM nas Unidades Básicas de Saúde responsáveis pelo matriciamento. No entanto, em unidades nas quais ele ocorre, tem se mostrado potente na formação dos trabalhadores, de forma geral. Uma das profissionais envolvidas aponta a importância de se trabalhar de forma menos pedagógica possível, possibilitando a expressão de sentimentos dos profissionais em relação aos usuários e às angústias produzidas pelo próprio trabalho.

Nunes et al. (2008) identificaram a coexistência de três modelos de cuidado em SM: o modelo biomédico humanizado; o psicossocial, com ênfase na instituiçáo e o psicossocial, com ênfase no território, revelando pontos de conflito na forma de vislumbrar a Reforma Psiquiátrica desejada e o alcance das práticas.

Podemos avaliar que em Betim, embora haja movimentos para sair dos CAPS, como os fóruns intersetoriais e o apoio matricial, o modelo continua centrado nesse dispositivo. Assim, há que se avançar na inovação e na criatividade de estratégias e mecanismos para manter vivo o movimento de desinstitucionalização. As experiências de EPS apontadas neste estudo podem contribuir para disparar e sustentar esse processo. 


\section{Considerações finais}

A história de construção dos serviços de Betim foi marcada por invenção, reflexão e formação. Os trabalhadores foram criando dispositivos a partir das necessidades das pessoas em sofrimento mental do município e de suas demandas, bem como das condiçôes reais e ao que era possível nos diferentes contextos políticos. Em vários momentos, realizaram-se propostas importantes de formação, com a participação maior dos trabalhadores. Em outros, identificou-se a vulnerabilidade trazida pelas mudanças de gestáo, desconstruindo projetos educativos de gestôes anteriores, tal como a residência multiprofissional.

Os trabalhadores conseguiram, ao longo dessa trajetória, sustentar alguns espaços de discussão, análise e reflexão de suas práticas e de seus referenciais teóricos. Foram atores ativos, saindo da condição de "recursos humanos" para o estatuto de atores implicados e comprometidos com a Reforma Psiquiátrica brasileira.

Percebemos, no entanto, que esses trabalhadores conviveram ao longo dos anos com oscilaçôes de investimentos no SUS e com a desvalorização de suas funçôes enquanto servidores públicos, se sentindo responsabilizados pela resolutividade dos serviços, mas convivendo com inúmeros desafios.

Atualmente, temos um aumento importante na demanda, bem como na complexidade dos casos, todavia, nacionalmente, estamos vivendo um processo acelerado de desmonte dos avanços alcançados pela reforma psiquiátrica, acarretando também perdas importantes nos dispositivos de formaçáo, enfraquecimento de práticas coletivas e colaborativas de reflexão do trabalho e de Educação Permanente.

Observamos que em Betim houve uma aproximação entre a universidade e a Saúde Mental, através de estágios ou de programas do Ministério da Saúde, como o Pró-Saúde e o PET-Saúde, propostas de educação interprofissional importantes para o trabalho no SUS. É necessário continuar fortalecendo esse vínculo, pois, ainda, é preocupante a formação dos novos trabalhadores, que se mantém centrada no modelo liberal, formando especialistas, de forma uniprofissional, sem articulação com as outras disciplinas.

Com a trajetória de formação dos trabalhadores de Betim, constatamos que a integração ensino-serviço pode ser uma ferramenta importante não apenas para os estudantes, mas também para a educação dos profissionais do SUS: ela pode 
favorecer a formação e a reflexão crítica do próprio trabalho e a universidade pode trazer elementos ricos para essa reflexão.

Também as supervisões são importantes dispositivos de EPS. Mas é importante que a "linguagem hermética" da psicanálise dê lugar a um esforço de comunicação entre as pessoas de diferentes formações.

Entendemos que esse estudo pode contribuir para demonstrar a importância da Educação Permanente, bem como da integração ensino-serviço, como uma estratégia de resistência e de fortalecimento do modelo de Atenção Psicossocial.

\section{Referências}

AMARANTE, P. Saúde Mental e Atenção Psicossocial. 4a. ed. Rio de Janeiro: Fiocruz, 2015.

ARBEX, D. Holocausto brasileiro. 1. ed. São Paulo: Geração Editorial, 2013.

BRASIL. Lei n ${ }^{\circ}$ 10.216, de 06 de abril de 2001. Dispóe sobre a proteção e os direitos das pessoas portadores de transtornos mentais e redireciona o modelo assistencial em Saúde Mental. Diário Oficial da União, Poder Executivo, Brasília, DF, 09 ab. 2001. Seção 1. p.2.

. Ministério da Saúde. Politica de educação e desenvolvimento para o SUS: caminhos para a educação permanente em saúde: pólos de educação permanente em saúde. Brasília: Ministério da Saúde, 2004. 68 p. - (Série C. Projetos, Programas e Relatórios).

. Ministério da Saúde. Conselho Nacional de Saúde. Princípios e diretrizes para a gestão do trabalho no SUS (NOB/RH-SUS). 3. ed. rev. atual. - Brasília: Ministério da Saúde, 2005.98 p. - (Série Cadernos Técnicos - CNS) - (Série J. Cadernos - MS)

. Ministério da Saúde. Ministério da Educação. Portaria Interministerial no 1.802, de 26 de agosto de 2008. Institui o Programa de Educação pelo Trabalho para a Saúde - PETSaúde. Diário Oficial da União, Poder Executivo, Brasília, DF, 27 Ago2008.Seção 1, p. 27.

. Ministério da Saúde. Política Nacional de Educação Permanente em Saúde. Brasília: Ministério da Saúde, 2009. 64 p. - (Série B. Textos Básicos de Saúde) (Série Pactos pela Saúde 2006; v. 9).

- Ministério da Saúde. Ministério da Educação. Programa Nacional de Reorientação da Formação Profissional em Saúde-Pró-Saúde: objetivos, implementação e desenvolvimento. Brasília: Ministério da Saúde, 2009. p.88 (Série C. Projetos, Programas e Relatório).

. Portaria n 3.088, de 23 de dezembro de 2011. Institui a Rede de Atenção Psicossocial para pessoas com sofrimento ou transtorno mental, incluindo aquelas com necessidades decorrentes do uso de crack, álcool e outras drogas, no âmbito do Sistema Único de Saúde (SUS). Diário Oficial da União, Brasília, DF, 30 dez. 2011. 
CAMPOS, K.F.C.; SENA, R.R.; SILVA, K.L. Educação permanente nos serviços de saúde. Escola Anna Nery, Rio de Janeiro, v. 21, n. 4, 2017. Disponível <http://www.scielo.br/scielo.php?script=sci_ arttext\&pid=S1414-81452017000400801\&lng=pt\&nrm=iso >. Acesso em 16 de julho de 2019.

CAVALCANTI, F.O.L; GUIZARDI, F.L. Educação Continuada ou Permanente em Saúde? Análise da Produção Pan-Americana da Saúde. Trabalho, Educação e Saúde, Rio de Janeiro, v. 16 n. 1, p. 99-122, 2018.

CECCIM, R.B.; FEUERWERKER,L.C.M. O Quadrilátero da Formação para a Área da Saúde: Ensino, Gestão, Atenção e Controle Social. PHYSIS: Revista Saúde Coletiva, Rio de Janeiro, v. 14, n. 1, p. 41-65, 2004.

DELGADO, P.G.G. Supervisão Clínico-Institucional: conceito e história. In: Augusto Nunes Filho. (Org.). Supervisão em Saúde Mental. 1. ed. Belo Horizonte: ESPMG, 2013, p. 18-27.

FERREIRA NETO, J.L. Psicologia, Politicas Públicas e o SUS. 2a . ed. Ampliada. São Paulo: Escuta, 2017.

GADAMER, H. Verdade e método. Petrópolis, RJ: Vozes, 1997.

GRILlO, M.J.C. Educação Permanente em Saúde: espaços, sujeitos e tecnologias na reflexão sobre o processo de trabalho. 222fl.Tese (Doutorado em enfermagem). Escola de Enfermagem, UFMG, Belo Horizonte, 2012.

HADDAD, J.; ROSCHKE, M.A.L.C; DAVINI, M.C. Educación Permanente de Personal de Salud. Washington: OrganizacionPanamericana de La Salud, 1994, 247 p. (Série Desarrollo de Recursos Humanos no100).

LIMA,I.C.B.F;PASSOS,I.C.F.ResidênciasIntegradasEmSaúdeMental:ParaAlémDoTecnicismo. Trabalho, Educação e Saúde, Rio de Janeiro, v. 17, n.2, 2019. Disponível em: <http://www.scielo. br/scielo.php?script=sci_arttext\&pid=S1981-77462019000200512\&lng=pt\&nrm=iso $>$ Acesso 15 jun. 2019.

MERHY, E.E. O desafio que a educação permanente tem em si: a pedagogia da implicação. Interface - Comunicação, Saúde, Educação, Botucatu, v.9, n.16, p.172-177, set.2004/fev.2005.

Educação Permanente em movimento - uma política de reconhecimento e cooperação, ativando os encontros do cotidiano no mundo do trabalho em saúde, questóes para os gestores, trabalhadores e quem mais quiser se ver nisso. Saúde em Redes. Porto Alegre, v.1, n.1,p. 07-14, 2015. Disponível em:<http://revista.redeunida.org.br/ojs/index.php/rede-unida/ article/view/309> . Acesso em 01 jul. 2019.

MINAYO, M.C.S; DESLANDES, S.F. (orgs.).Caminhos do pensamento: epistemologia e método. Rio de Janeiro: FIOCRUZ, 2008.

MINAYO, M.C.S. O desafio do conhecimento: pesquisa qualitativa em saúde. 14a .ed. São Paulo: Hucitec, 2014. 
NUNES, K.G. Reforma psiquiátrica no Brasil: Um estudo sobre a trajetória de Betim, Minas Gerais. Santa Cruz do Sul: EDUNISC, 2009.

NUNES, M. et al. A dinâmica do cuidado em saúde mental: signos, significados e práticas de profissionais em um Centro de Assistência Psicossocial em Salvador, Bahia, Brasil.Cadernos de Saúde Pública. Rio de Janeiro, v. 24, n. 1, p. 188-196, 2008. Disponível em: <http://www.scielo. br/scielo.php?script=sci_arttext\&pid=S0102-311X2008000100019>. Acesso em 30 jul. 2019.

ONOCKO CAMPOS, R. et al. Pesquisa Avaliativa em Saúde Mental: Desenho Participativo e Efeitos da Narratividade. 2a. ed. São Paulo: Hucitec, 2013.

ORGANIZACIÓN PANAMERICANA DE LA SALUD - OPAS. Educación permanente ensalud: informes finales de tres grupos de trabajo: Rol de La Universidad. Washington, 1992: Monitoreo de procesos educativos, Antigua, 1992. Washington, D.C.: OPAS, 1993. 54 p. (Seriedesarrollo de recursos humanos; 94).

PEDUZZI M. Educação Interprofissional para o desenvolvimento de competências colaborativas em saúde. In TOASSI R.F. (org.). Interprofissionalidade e formação na saúde: onde estamos? [recurso eletrônico]. 1. ed. - Porto Alegre: Rede UNIDA, 2017. P. 40-48. Disponível em: <http://historico.redeunida.org.br/editora/biblioteca-digital/serie-vivencias-em-educacaona-saude/vol-06-interprofissionalidade-e-formacao-na-saude-pdf>. Acesso em 15 nov. 2019.

RADKE, M.B.; CECCIM, R.B. Educação em saúde mental: ação da reforma psiquiátrica no Brasil. Saúde em Redes, Porto Alegre, v. 4, n.2, p. 19-36, 2018. Disponível em: <http://revista. redeunida.org.br/ojs/index.php/rede-unida/article/view/845/279>. Acesso em 30 jul. 2019.

SAMPAIO, J.J.C. et al.. O trabalho em serviços de saúde mental no contexto da reforma psiquiátrica: um desafio técnico, político e ético. Ciência \& Saúde Coletiva. Rio de Janeiro, v.16, n.12, p. 46854694, 2011. Disponível: <www.scielo.br/pdf/csc/v16n12/17.pdf>. Acesso: 24 jul. 2019.

SILVA, C.R. A extensão universitária em saúde mental: por uma formação crítica.199 fl. Dissertação (Mestrado em de Psicologia Social). Universidade Federal de Minas Gerais; Belo Horizonte, 2013.

SILVA, K.L. et al. Análise dos discursos referentes à educação permanente em saúde no Brasil (1970 a 2005). Trabalho, Educação e Saúde. Rio de Janeiro, v.17, n.2, 2019. Disponível em: $<$ http://www.scielo.br/scielo.php?script=sci_arttext\&pid=S1981-77462019000200200\&lng=pt \&nrm=iso>. Acesso 15 jun. 2019.

SILVA, N.S. et al. Desenvolvimento de recursos humanos para atuar nos serviços de saúde mental. Texto \& Contexto-Enfermagem, Florianópolis, v. 22, n. 4, p. 1142-1151, 2013. Disponível em: <http://www.scielo.br/scielo.php?script=sci_arttext\&pid=S0104-07072013000400033>. Acesso: 26 jul. 2019.

VASCONCELOS, E.M. Abordagens psicossociais: história, teoria e trabalho no campo. 2a .ed. São Paulo: Hucitec, 2009. V. 1. (SaúdeLoucura; v.24). 


\section{Abstract}

Permanent Health Education: narrative of the Mental Health workers of Betim I Minas Gerais

The creation of services to replace asylums has brought numerous challenges, including the training of its workers. Faced with this challenge, it was necessary training in the services themselves. The present study seeks to understand this phenomenon, from the trajectory of Mental Health workers in the city of Betim, Minas Gerais. The methodological framework was based on qualitative research guided by dialectical hermeneutics. The data collection instruments were narrative interviews and focus group. We understand that workers learned to work in psychosocial care within their own services, from the multiprofessional team and the following devices: meetings, forums, workshops. They were active actors, promoting seminars and various meetings; as well as having, at times, clinical and institutional supervision. The teaching-service integration also favored the permanent education of the workers. However, in recent years there have been difficulties in sustaining such training.

> Keywords: permanent health education; mental health; qualitative research. 